\title{
Luria's model of the functional units of the brain and the neuropsychology of dreaming
}

\author{
Arnoldo Téllez ${ }^{\star}$, Teresa de J. Sánchez \\ School of Psychology, Universidad Autónoma de Nuevo León, Nuevo León, Mexico \\ *Corresponding autor. E-mail: arnoldo.tellez@uanl.mx
}

\begin{abstract}
Traditionally, neuropsychology has focused on identifying the brain mechanisms of specific psychological processes, such as attention, motor skills, perception, memory, language, and consciousness, as well as their corresponding disorders. However, there are psychological processes that have received little attention in this field, such as dreaming. This study examined the clinical and experimental neuropsychological research relevant to dreaming, ranging from sleep disorders in patients with brain damage, to brain functioning during REM sleep, using different methods of brain imaging. These findings were analyzed within the framework of Luria's Three Functional Unit Model of the Brain, and a proposal was made to explain certain of the essential characteristics of dreaming. This explanation describes how, during dreaming, an activation of the First Functional Unit occurs, comprising the reticular formation of the brainstem; this activates, in turn, the Second Functional Unit - which is formed by the parietal, occipital, and temporal lobes and Unit L, which is comprised of the limbic system, as well as simultaneous hypo-functioning of the Third Functional Unit (frontal lobe). This activity produces a perception of hallucinatory images of various sensory modes, as well as a lack of inhibition, a non-selfreflexive thought process, and a lack of planning and direction of such oneiric images. Dreaming is considered a type of natural confabulation, similar to the one that occurs in patients with frontal lobe damage or schizophrenia. The study also suggests that the confabulatory, bizarre, and impulsive nature of dreaming has a function in the cognitiveemotional homeostasis that aids proper brain function throughout the day.
\end{abstract}

Keywords: dreaming, brain, neuropsychology, functional units, Luria's model

\section{Introduction}

Since its beginning, neuropsychology has focused on identifying the brain functions corresponding to psychological processes known as "higher processes", such as attention, motor skills, perception, memory, language, and conscience, as well as their corresponding disorders (e.g., inattention, apraxia, agnosia, aphasia). However, there are psychological processes that have received little attention in 
this field; among them is the process of dreaming. Over the last few decades, interesting neuropsychological findings have started to surface about the relationship between the production and recollection of oneiric processes. Such research has been examined here. We can start by asking ourselves: Are dreaming, or dreams, a subject of study for neuropsychology? Although no one definition of neuropsychology has been accepted throughout the field, Alexander R. Luria (1974), considered the founder of modern neuropsychology, defined it as follows: "A new branch of scientific knowledge, the main aim of which is to investigate the role of specific brain systems, in the complex forms of mental activity." According to this definition, we can pose the following question: Is dreaming a complex form of mental activity?

To answer this question, it would be of great help to describe the phenomenology of dreaming. Dreaming is an active psychophysiological process that involves the presence of perceptible hallucinatory images during sleep (i.e., the visual, auditory, tactile, kinesthetic, and linguistic kind), and cognitive activity with an emotional content of variable intensity that has been generated internally (Desseilles, Dang-Vu, Sterpeinch, \& Schwartz, 2011). The content of the dream is bizarre by nature, with bizarre defined as featuring incongruities and discontinuities in the time, space, and the characters that appear in it (Corsi-Cabrera et al., 2003). Furthermore, there is a lack of control over the course of dream scenes, in which there are often violations of the laws of physics. All of this is due to a lack of critical thinking that can evaluate the coherence, or the lack thereof, of what is happening, so there is a passive and uncritical acceptance of everything that happens (Corsi-Cabrera et al., 2003). Arthur W. Epstein (1984) says that "dream formation involves a complex psychological activity that integrates memory, language, and thinking itself". If, after this, we assume that reality training is a complex form of mental activity, the next questions would be: Which particular brain systems are involved in this process? What are the differences between the neuropsychological systems involved in the conscious processes of wakefulness, and the ones involved in dreaming?

Obviously dreams have interested and captivated humanity since ancient times. It was not until 1900, however, that Sigmund Freud (1966) published his book "The Interpretation of Dreams," which included the first scientific approach to the subject from a purely psychological point of view. The first approach toward psychobiological scientific research on the subject of dreaming occurred in 1953 when Aserinsky and Kleitman from the University of Chicago published their research, which stated that sleep with rapid eye movement, known as REM sleep, is frequently associated with dream recall. Since then, we have learned that human sleep is made up of two phases: REM sleep, which is generally associated with dreaming, and nonREM sleep, or sleeping without rapid eye movement, from which very few dreams are recalled. In the REM phase, the eyes move rapidly in all directions, and upon waking up, people frequently report having dreamt. During this phase, there is also an increase of electroencephalographic (Rechtschaffen \& Kales, 1968) and cerebral metabolic activity, which is equal to or greater than that activity during wakefulness (Braun et al., 1997; Madsen, 1993; Maquet et al., 1996; Sakai, Meyer, Karacan, Derman, \& Yamamoto, 1980). Penis erection also occurs in males (Fisher, 1973), as well as increases in heart rate (Aldredge \& Welch, 1973; Žemaityte, Varoneckas, 
\& Sokolov, 1984). All this intense psychophysiological activity is accompanied by muscle atonia (Berger, 1961), the function of which, some authors have mentioned, is to avoid the translation of the dream into action (Fisher, 1973). On the other hand, we find non-REM sleep characterized by a decrease in psychophysiological activity in general (Téllez, 1998).

\section{Luria's model of brain functioning: The Three Functional Units model}

As has been previously mentioned, dreaming is a psychophysiological process as active as wakefulness; however, little is known about the neuropsychological systems involved. Therefore, the objective of this article is to present a neuropsychological model of dreaming based on the most relevant clinical, experimental, psychophysiological, and neuropsychological research. To present our proposal about the generation and bizarre content of dreaming, we took as a general framework Luria's Three Functional Units Model (Luria, 1974), which attempts to explain the neuropsychological functioning of human beings during wakefulness.

A) The First Unit is made up by the structures of the brainstem, specifically, the reticular activation system, thalamus, and monoaminergic cell groups in the brainstem, which function to activate and keep the general cortical tone needed to activate, the cerebral cortex, generating a state of alertness (Magoun, 1964; Grønli, \& Ursin, 2009).

B) The Second Unit is formed by the parietal, occipital, and temporal lobes, and is responsible for obtaining, processing, integrating, and storing sensory information from the environment.

C) The Third Unit is formed by the frontal lobe, which is in charge of the selection, planning, execution, and direction of a person's pattern of behavior, as well as its evaluation. It also includes vital cognitive functions such as sustained attention, awareness, and insight (Luria, 1974; Cummings, 1995; Stretton, \& Thompson, 2012).

Although Luria does not explicitly mention it, we believe it is convenient to incorporate the limbic system as a Fourth Unit:

D) Unit L, which includes the hippocampus, amygdala, and fornix, comprises the limbic system, as well as para-limbic structures, such as the cingulate gyrus and the para-hippocampal and orbitofrontal regions. This Unit is responsible for emotional responses and the consolidation of the memory (Téllez et al., 2002).

\section{The Three Unit Model during REM sleep}

During REM sleep, there is an activation of the First Unit similar to what occurs in the state of wakefulness, which manifests itself with an increase of the electroencephalographic and metabolic activity in most regions of the brain. Hobson and Stickgold (1995) found that during REM sleep, activation of the brainstem starts in the cholinergic system on a pontine level. Studies with positron emission computerized tomography (PET) have confirmed an increase in the brainstem's metabo- 
lism (Braun et al., 1997), which generates electroencephalographic and metabolic activation, as well as stimulates of the posterior cortical and subcortical areas, especially the limbic-emotional system.

However, the activation of the First Unit during dreaming is not completely the same as in wakefulness because a cortical motor inhibition occurs, producing motor paralysis (Berger, 1961; Fisher, 1973).

The activation of the First Unit also differs from that in wakefulness, in that it produces a greater stimulation of the structures in Unit $\mathrm{L}$, the unit that produces emotional activation (Calvo, 1995). This has been confirmed by experimental studies in animals and humans. For example, it has been reported that the stimulation of the cingulate gyrus in humans causes complex hallucinatory phenomena, emotional changes, rapid eye movement, and oneiric sensation. Similar changes are reported following the stimulation of the hippocampus and amygdala (Calvo, 1995). It can be inferred that any variable that increases limbic system activity during dreams can cause differences in emotional intensity, ranging from little emotional content to nightmares.

As an example, the cases of patients with areas of epileptogenic activity in the limbic and paralimbic regions (Unit L), as in the case of the temporal lobe epilepsy, show a higher dream-recall frequency than patients with generalized tonic-clonic seizures and normal people (Epstein, 1984; Maquet et al., 1996). Some authors have found that individuals with limbic hyper-function, as indexed by increased scores on the Limbic System Checklist, report more threatening dream content than others (Peterson, Henke, \& Hayes, 2002).

As a consequence of the activation of Unit 1, Unit 2 is stimulated, generating activation in visual, perceptive-imaginative, auditory, linguistic, spatial, and tactile functions.

Studies with PET have found that the visual and auditory secondary areas are especially metabolically active during REM sleep, even above levels found in wakefulness (Braun et al., 1997; Madsen, 1993). The activation of the visual system is manifested through PGO spikes (bioelectric activity that comes in a synchronized way from the pons, lateral geniculate body, and the occipital cortex) that are associated with rapid eye movement, giving way to dreams with visual predominance (Calvo, 1995; Hong, Gillin, Dow, \& Buchsbaum, 1995). Several studies agree that lesions in the areas involved in visuospatial processing and representation in Unit 2 , result in a reduction in, or elimination of, dreaming, a neuropsychological syndrome called "anoneria". These disturbances of the dreaming process are positively correlated with the appearance of some type of agnosia (Doricchi \& Violani, 1992; Kerr \& Foulkes, 1981; Murri et al., 1992; Peña-Casanova, Roig-Rovira, Bermudez, \& Tolosa-Sarro1985). For example, Peña-Casanova et al. (1985) reported a case of a patient with a lesion in the left temporo-occipital region due to a cerebrovascular accident. This patient lost the ability to dream and also showed optic aphasia, optic apraxia, aphasia without agraphia, and color agnosia.

In the meantime, Unit 3, or the frontal lobe, simultaneously suffers an inhibition of some of its regions and an activation of others. The frontal lobe can be divided into two regions: the motor region (Brodmann areas 4, 6, and 8) and the non-motor region, or prefrontal lobe (Areas 9, 10, 11, 44, 45, 46, and 47). The prefrontal lobe is divided into three regions: 
1) The dorsomedial region, which is associated with executing functions such as the formulation of goals, working memory, planning, execution of plans, and the self-regulation of behavior; 2) the orbital frontal region, which is related to the inhibition and control of impulses and social tact; and 3) the medial region, which has been related to motivation and the process of thinking what another person is thinking, also known as mentalization, a second order process of representation relevant to social skills (Frith, 2007). In general, the prefrontal lobe has been associated with selection functions, programming, and direction of behavioral planning, and impulse inhibition, as well as critical and reflexive thought (Cummings, 1995; Luria, 1974; Tsvetkova, 1996).

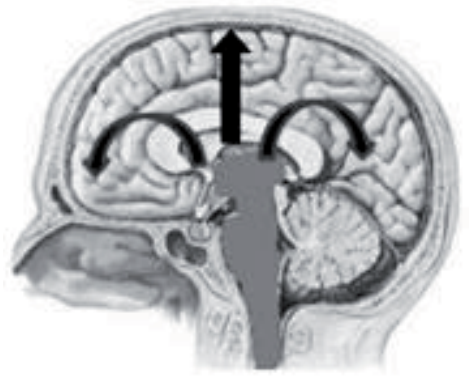

Unit 1

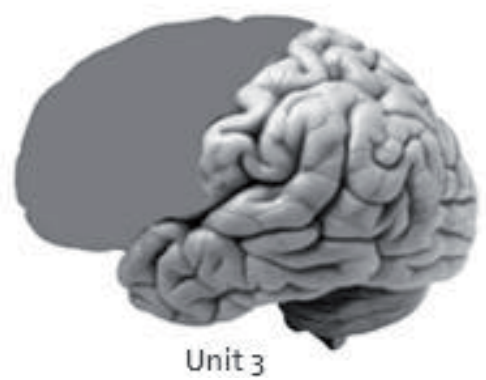

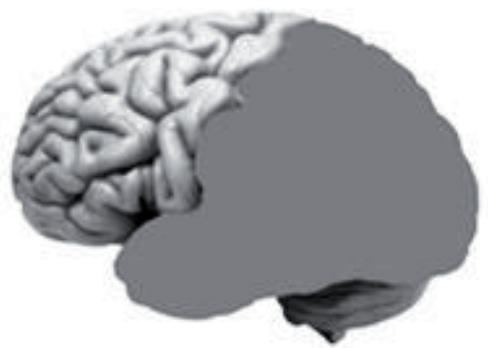

Unit 2

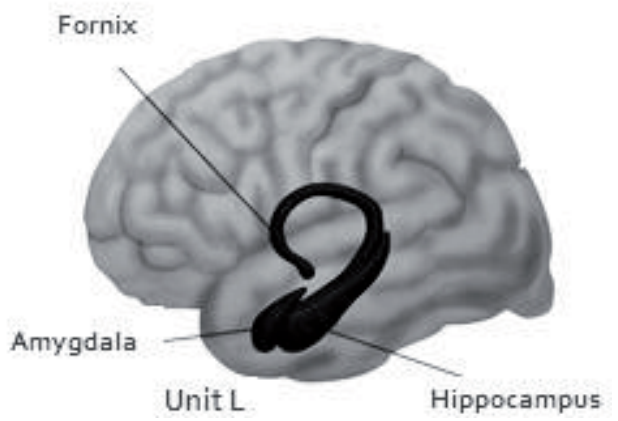

Figure 1. This picture shows the four Functional Units of the Brain: Unit 1(reticular system), Unit 2 (parietal, occipital and temporal lobes), Unit 3 (Frontal lobe) and Unit L (limbic system).

It has been proven through PET and functional magnetic resonance imaging (fMRI) that during dreaming, there is an activation of the primary and supplementary motor areas, such as the frontal ocular area (Brodmann's area 8), which is activated by Unit 1 and then collaborates in producing the rapid eye movements of REM sleep (Hong et al., 1995). The activation of the supplementary motor area (Brodmann's area 6) and primary motor area (Brodmann's area 4) produces a programming and activation of a sequence of corporal movements during the oneiric content; but said activation remains on a representational level, because an inhibition occurs in the caudal region of locus coeruleus located in the pons of the brain stem (Unit 1) due to hyperpolarization of the motoneurons in the spinal cord. This 
generates a general muscle paralysis (with the exception of ocular movement), that prevents the dream from becoming an action (Berger, 1961; Jouvet, Sastre, \& Sakai, 1981). Other areas that are activated are the prefrontal medial region and the part that corresponds to the anterior region of the cingulate gyrus (Braun et al., 1997; Buchsbaum et al., 1989). These structures have a connection with Unit L.

Moreover, the dorsolateral region of the prefrontal lobe (Brodmann's areas 9, $10,45,46,47)$ and the orbital frontal region (Brodmann's areas 11 and 12) show an inhibition during dreaming. Madsen (1993), using PET, found a drop in metabolism in the orbitofrontal region during REM sleep. Using the same technique, Maquet et al. (1996) found a decrease in the activity of the frontal lobes and an increase in the amygdaloid complex. It is well-established that lesions or dysfunction in this area in neuropsychological patients result in uninhibited, impulsive, and bizarre behavior.

Years later, using PET with $\mathrm{H} 2150$ radioactive tracers, which are the most suitable for sleep research, Braun et al. (1997) found low metabolism in the orbitofrontal and dorsolateral regions of the prefrontal lobe during REM sleep, as well as in the inferior parietal association, and simultaneously, an increase in metabolism in the visual and auditory association areas of Unit 2. Doricchi and Violani (1992) and Murri et al. (1992) found that frontal lesions do not affect dreaming, and some patients with frontal damage show an increased frequency of nightmares (Colace1, Salotti, \& Ferreira, 2015), indirectly confirming the previously mentioned PET findings. This also supports the hypothesis that Unit 3 is inactive and not necessary for the dreaming process.

Other indications that the prefrontal lobe is hypo-functioning during dreaming come from comparing studies of interhemispheric and intra-hemispheric electroencephalographic correlation during wakefulness, REM, and non-REM sleep. Corsi-Cabrera et al. (2003) found an absence of electroencephalographic correlation between the frontal and perceptual regions, as well as an increased correlation among the perceptual regions. These researchers suggested that this temporary dissociation between the executive and perceptual areas is the cause of the characteristic bizarreness of dreams.

That being said, it can be expected that, upon the activation of Unit L and a simultaneous decrease in the functioning of the prefrontal lobe during wakefulness, any person could behave in an uninhibited, impulsive or aggressive way, with difficulties in planning and self-regulation. Such can be the case of people with schizophrenia (Gershon \& Rieder, 1992; Goldberg, 2002) and major depression (Beck, 2008), and the 75\% of criminals who exhibit low metabolism in the prefrontal lobe during wakefulness (Goldberg, 2002; Gibbs, 1995). During REM sleep in normal people, there is an increase in the activity of Unit $\mathrm{L}$ and a decrease in Unit 3; however, we cannot observe the behavioral effects, due to the activation of the cerebral mechanisms that produce the muscle paralysis that comes with this type of sleep, preventing the body from acting out dreams.

On the contrary, experiments with cats that had the coeruleus alfa nucleus damaged - the nucleus which seems to be responsible for the motor paralysis during REM sleep - have caused these animals to translate their "dreams" into behavior, which is generally manifested in rapid behavioral sequences of, for instance, attack, rage, and grooming. These behaviors are not directed towards an objective, 
because when a piece of meat or a mouse is placed near them, they do not seem to notice them, and they continue with their stereotypical behavior. Furthermore, the cats' pupils display miosis and are covered by the nictitating membranes in same way as during REM sleep. This phenomenon has been called "oneiric behavior" (Jouvet et al., 1981). Jouvet et al. (1981) make an interesting observation about animal behavior: "Some cats that exhibited friendly behavior during daytime, showed a large incidence rate of aggressive behavior during REM sleep". This can be interpreted as the result of a broad activation of Unit L without a cortical regulation (Buchsbaum et al., 1989).

In the case of humans, it is interesting to find a clinical sleep disorder that is similar to the "oneiric behavior" experimentally induced in cats. This disorder is named "REM sleep behavior disorder" (RBD) and is characterized by the absence of the muscle paralysis which is customary during this stage of sleep, as a result of neurological related disorders. In contrast to sleepwalking, which occurs during the slow-wave stage of non-REM sleep and in people who generally behave in a peaceful way, patients with RBD frequently have accidents and carry out physical and verbal assaults on other people during these episodes (Tellez, 1998; Schenck, Bundlie, Patterson, \& Mahowald, 1987; Schenck, Milner, Hurwitz, Bundlie, \& Mahowald, 1989). This behavior is very similar to that of the Jouvet et al. (1981) cats and is the result of the activation of Units 1,2 , and especially $L$, along with the simultaneous inhibition of the prefrontal lobe. RBD seems to be an early warning sign of Parkinson's disease, as some authors have noted that $65 \%$ of patients with this sleep disorder develop the disease within an average of nine years after RBD shows up (Abbott, 2005), indicating the degenerative etiology of this disorder. Thus, RBD also represents an etiological model for the study of oneiric behavior.

\section{The model of the Four Units of dreaming: A proposal}

The findings cited above allow us to suggest that the nature of the oneiric content during dreaming is caused by the simultaneous inhibition of (1) the prefrontal lobe in the dorsolateral region - the region that is in charge of the executive functions, (2) the orbitofrontal region, that relates to the regulation of limbic impulses, as well as (3) the parietal-temporal-occipital (PTO), that is involved in visuo-spatial recognition, symbol processing, and face and object recognition. Thus, the main proposal of this model, is that the characteristics of the oneiric content -that is, the lack of planning and control of critical and coherent thought toward what is dreamt, as well as the ease by which emotional and motivational impulses emerge in dreams - basically correspond to an increase in the activity of Unit 1, 2 (with the exception of the PTO region), Unit L, and the medial region of the prefrontal lobe that occurs simultaneously with the inhibition of the dorsolateral and orbital regions of Unit 3 (Figure 1). This leads us to think of the oneiric process as basically a process of confabulation, suggesting that dreaming is a type of normal confabulation that happens every night in a cyclical way, but does not differ much from the confabulatory thoughts of patients with frontal lobe damage. Luria (1974) mentioned that the confabulations of these patients are similar to the oneiric states in terms of the loss of the selectivity of mental processes, which is typical of the normal conscious life (Figure 1). 
Meanwhile, Koukkou and Lehman (1983) have suggested that the cerebral state of an adult during dreaming corresponds functionally to the state of wakefulness during childhood, based on the similarity of the electroencephalographic activity of the different phases of sleep and in human development phases. They suggest that every time we dream, there is an age regression in our psychophysiological functioning that causes us to have access to cognitive memories and strategies of that younger age. They also suggest that these cognitive strategies during adult dreaming are equivalent to the processes of fantasy, and are far from the reality thought of a young child during wakefulness (Piaget's preoperational stage). Some data indicate that the prefrontal lobe does not reach maturity until between the ages of 10 to 12 years (Welsh \& Pennington, 1988). Then, according to this hypothesis, a functional regression of cognitive activity in dreaming would imply incomplete functioning of the prefrontal lobe.

On the other hand, the recollection of dreams becomes interesting. It is well known that dreams are difficult to remember in wakefulness (Fisher, 1973). This is possibly explained through the state-dependent theory (Koukkou \& Lehmann, 1983). According to the model presented in this research, dreams are difficult to remember precisely because of the lack of working memory due to the relative deactivation of the prefrontal lobe. It has been proven through fMRI that the degree of activation of the frontal lobe and the para-hippocampal region of the limbic system during the presentation of semantic and visual non-verbal information predicts its subsequent recall, showing the important role of these two structures in memory (Brewer, Zhao, Desmond, Glover, \& Gabrieli, 1998; Wagner et al., 1998). During dreaming, only the limbic region is activated, not the prefrontal; this fact produces a partial or total loss of memory of the oneiric content upon waking up in most people (Figure 1).

We can conclude that dreams, as well as cognitive activity in wakefulness, come in various forms and contents. For example, there could be dreams with a very high emotional content due to the intense activity of Unit L, a high imaginative-visual content with an increase of activity in the right hemisphere of Unit 2, or a high narrative-linguistic content produced by the left hemisphere, but always partnered with an inhibition of the dorsolateral and basal regions of Unit 3. It has been shown that "lucid" dreams are characterized by "being able to freely remember the circumstances of waking life, to think clearly, and to act deliberately upon reflection, all while experiencing a dream world that seems vividly real" (LaBerge, 1990). These are dreams where the control and direction of the oneiric process are maintained, and the dreamer is aware that he is dreaming. This is the result of an exceptional and sudden reactivation of the functioning of the dorsolateral and medial regions of the left prefrontal lobe and the temporoparietal region during REM sleep. During wakefulness, complex information processing is promoted by these regions, but they are not active during non-lucid dreaming. This pattern of brain activity explains the recovery of the executive metacognitive abilities and voluntary control that characterizes lucid dreaming (Dresler et al., 2012; Noreika, Windt, Lenggenhager, \& Karim, 2010).

Foulkes (1982), whose studies were also based on Luria's work, suggested another model of brain functioning during dreaming. He suggested that dreaming is generated verbally in the left frontal lobe, which remains functional during REM 
sleep and "that it competes with the basal affective and posterior associative systems that are left uninhibited during sleep". However, this model has not been entirely confirmed by recent studies with PET (Braun et al., 1997; Buchsbaum et al., 1989; Madsen, 1993; Maquet, 1996).

\section{The function of dreaming: Cognitive-emotional homeostasis}

We propose that the inhibition of prefrontal lobe functioning and the increase in activity of Unit L during REM sleep can have a cognitive and emotional homeostatic function that is important for good psychological performance during wakefulness. This process allows for an increase in prefrontal lobe functioning and a decrease of limbic activity throughout the day, allowing better impulse control, planning, and self-regulation of behavior.

This evaluation agrees with the "Motivational Theory of REM Sleep" by Vogel (1979), which suggests that the function of the REM phase of dreaming is to decrease the impulse-motivated behavior during wakefulness. This researcher proposes this theory in light of the observation that the selective deprivation of REM sleep in animals produces increases in aggressive, sexual, and food-seeking behaviors. It was also noticed that the deprivation of REM sleep in patients experiencing endogenous behavior improves their symptomatology (Vogel, Vogel, McAbee, \& Thurmond, 1980). Meanwhile, Vogel (1979) argued that the decrease in the amount of REM sleep as a consequence of the use of antidepressant drugs, is caused by an increase in impulse-motivated behavior during wakefulness, and therefore, a clinical improvement of depression.

In his new model to explain depression, Beck (2008) affirms that in patients with depression, there is a hyperactivity of the amygdala that causes an excessive reactivity in the presence of negative events, and hypo-activity of the prefrontal lobe that prevents a proper interpretation of events and counteracts the high activity of the amygdala. In fact, patients with depression show an increase in the metabolism of the dorsolateral region of the prefrontal lobe during REM sleep instead of the decrease which is observed in subjects without depression. This then causes a decrease in activity in the dorsolateral region of the prefrontal lobe and an increase of activity of the limbic system, preventing the regulation and evaluation of social contexts and circumstances, sensations, and emotions in a suitable way during wakefulness (Nofzinger, 2005). As we have examined, the prefrontal lobe of the human being is extremely sensitive to sleep; its functioning is altered by sleep deprivation, and it benefits and recovers with sleep of good quality and quantity (Muzur, Pace-Schott, Hobson, 2002). The usual effects of sleep deprivation on the prefrontal lobe's functions are well known and include irritability, lack of attention and concentration, working memory impairments, and lack of self-regulation skills (Durmer \& Dinges, 2005). Sleep deprivation makes us more sensitive to emotional and stress-induced stimuli (Vandekerckhove \& Cluydts, 2010).

This finding also favors the hypothesis that frontal hypo-activity and limbic hyperactivity during REM sleep is really homeostatic, meaning that an increase in emotional and motivational activity works as an escape valve during the night without the logical, reasoned, and regulating activity of the prefrontal lobe, and 
that during the day, the limbic activity decreases, and the dorsolateral and orbital activity of the prefrontal lobe increases.

Schwartz and Maquet (2002) suggested that the bizarre content of dreaming is similar to certain neuropsychological syndromes that produce visual and spatial agnosia. During REM sleep, the cerebral structures that are activated and deactivated are similar to the cerebral regions damaged in the cited neuropsychological syndromes. In addition to the content of dreaming, there is an absence of control over the course of the dream scenes due to lack of the critical thinking that evaluates the coherence of what is happening; therefore, there is a passive and non-critic acceptance of what is occurring during the dream (Corsi-Cabrera et al., 2003).

That is the reason why Hobson and Stickgold (1995) stated that dreaming represents a model for explaining schizophrenia. This is because of the cognitive and emotional similarities between them, such as the exaggeration of the emotional activity that contributes the deterioration of rationality and to the lack of selective attention and direction of cognitive knowledge which, besides being grotesque, contains a great quantity of confabulations. Furthermore, both conditions show similar neuropsychological functioning: a hypo-functioning of the frontal lobe and an activation of Unit L. These characteristics impede the schizophrenic patient and the dreamer from organizing their thoughts, integrating them with emotions, and turning them into appropriate actions. Schizophrenia studies with PET have shown diminished frontal lobe functioning.

It can be said that dreaming is a state similar to a "schizophrenic or frontal lobe syndrome," but temporary, normal, and healthy, so that the next day, the brain can carry out its homeostatic function, and promote optimal functioning of the dorsolateral and orbital region of the frontal lobe during wakefulness. In this way, the frontal lobe can carry out the functions of planning, execution, evaluation, attention, working memory, self-observation, better impulse control, and proper decision-making, allowing the individual to carry out a proper everyday life of social interaction.

Dresler et al. (2014) found that in lucid dreaming, the active brain structures are the ones that malfunction in schizophrenia, and this is what prevents patients from becoming aware of their pathological state. We can state that "the oneiric craziness of every night" is a necessary escape valve permitting the person to act sanely during the state of wakefulness. According to Solms (2000), a renowned researcher in the neuropsychology of dreaming, these data support the essential idea proposed by Freud (1966), who maintained that one of the functions of dreaming was to allow instinctive impulses to emerge (limbic) without the censorship mechanism (dorsolateral and orbital prefrontal regions), thus allowing the attainment of repressed desires in a safe way.

Finally, we would like to mention several research questions that result from this article: What is the oneiric content in a patient with prefrontal damage? How can it be proven that the hypo-functioning of the prefrontal lobe and the limbic hyper-functioning during dreaming fulfill a homeostatic need for good psychological functioning during wakefulness? There is a proven antidepressant effect of REM sleep deprivation (Vogel et al., 1980; Nofzinger, 2005). Does it produce changes in 
the biochemical functioning of the prefrontal lobe and the limbic system? Answering these and other questions will allow continuing progress in this new and interesting field in the neurosciences: the neuropsychology of dreaming.

\section{Conclusions}

Luria's Model of the Brain's Functional Units can be used to explain the generation of dreams and their characteristics. The similarity between dreaming, frontal lobe syndrome and schizophrenia are stressed, especially in terms of the confabulations, the lack of impulse control, and the lack of self-direction and monitoring that occurs in these disorders. In addition, the suggested hypothesis of the homeostatic character of REM sleep favors the idea that the brain works in an inverse way during the state of wakefulness to assist better psychological functioning of the individual.

\section{References}

Abbott, A. (2005). While you were sleeping. Nature, 437(7063), 1220-1222. doi: 10.1038/4371220a Aldredge, J. L., \& Welch, A. J. (1973). Variations of heart rate during sleep as a function of the sleep cycle. Electroencephalography and Clinical Neurophysiology, 35(2), 193-198. doi: 10.1016/0013-4694(73)90176-4

Aserinsky, E., \& Kleitman, N. (1953). Regularly occurring periods of eye motility and concomitant phenomena during sleep. Science, 118, 273-274. doi: 10.1126/science.118.3062.273

Beck, A. T. (2008). The evolution of the cognitive model of depression and its neurobiological correlates. The American Journal of Psychiatry, 165(8), 969-977. doi: 10.1176/appi. ajp.2008.08050721

Berger, R. J. (1961). Tonus of extrinsic laryngeal muscles during sleep and dreaming. Science, 134(3482), 840. doi: 10.1126/science.134.3482.840

Braun, A. R., Balkin, T. J., Wesenten, N. J., Carson, R. E., Varga, M., Baldwin, P., Selbie, S., Belenky, G., \& Herscovitch, P. (1997). Regional cerebral blood flow throughout the sleep-wake cycle: an H2 150 PET study. Brain, 120(7), 1173-1197. doi: 10.1093/brain/120.7.1173

Brewer, J. B., Zhao, Z., Desmond, J. E., Glover, G. H., \& Gabrieli, J. D. E. (1998). Making memories: Brain activity that predicts how well visual experience will be remembered. Science, 281(5380), 1185-1187. doi: 10.1126/science.281.5380.1185

Buchsbaum, M. S., Gillin, J. C., Wu, J., Hazlett, E., Sicotte, N., Dupont, R. E., Bunney, W. E. (1989). Regional cerebral glucose metabolic rate in human sleep assessed by positron emission tomography. Life Sciences, 45(15), 1349-1356. doi: 10.1016/0024-3205(89)90021-0

Calvo, J. M. (1995). El sueño REM y el sistema límbico: Aspectos biológicos de las ensoñaciones. En J. Velázquez (Ed.), Temas Selectos de Neurociencias. México: UAM Iztapalapa.

Colace, C., Salotti, P., \& Ferreira, M. (2015). Reduction of dream bizarreness in impaired frontal cortex activity: A case report. Sleep and Hypnosis, 17, 1-2.

Corsi-Cabrera, M., Miró, E., del-Río-Portilla, Y., Pérez-Garcia, E., Villanueva, Y., \& Guevara, M. A. (2003). Rapid eye movement sleep dreaming is characterized by uncoupled EEG activity between frontal and perceptual cortical regions. Brain and Cognition, 51(3), 337-345. doi: 10.1016/S0278-2626(03)00037-X

Cummings, J. L. (1995). Anatomic and behavioral aspects of frontal-subcortical circuits. Annals of the New York Academy of Sciences, 769(1), 1-14. doi: 10.1111/j.1749-6632.1995. tb38127.x 
Desseilles, M., Dang-Vu, T. T., Sterpenich, V., \& Schwartz, S. (2011). Cognitive and emotional processes during dreaming: a neuroimaging view. Consciousness and Cognition, 20(4), 9981008. doi: 10.1016/j.concog.2010.10.005

Doricchi, F., \& Violani, C. (1992). Dream recall in brain-damaged patients: A contribution to the neuropsychology of dreaming through a review of the literature. In J. S. Antrobus, \& M. Bertini (Eds.), The Neuropsychology of Sleep and Dreaming (pp. 99-133). New Jersey: Psychology Press.

Dresler, M., Wehrle, R., Spoormaker, V. I., Koch, S. P., Holsboer, F., Steiger, A., Obrig, H., Sämann, P. G., \& Czisch, M. (2012). Neural correlates of dream lucidity obtained from contrasting lucid versus non-lucid REM sleep: A combined EEG/fMRI case study. Sleep, 35(7), 1017-1020. doi: 10.5665/sleep.1974

Dresler, M., Wehrle, R., Spoormarker, V. I., Steiger, A., Holsboer, F., Czisch, M., \& Hobson, J. A. (2014). Neural correlates of insight in dreaming and psychosis. Sleep Medicine Reviews, 20, 92-99. doi: 10.1016/j.smrv.2014.06.004

Durmer, J. S., \& Dinges, D. F. (2005). Neurocognitive consequences of sleep deprivation. Seminars in Neurology, 25(1), 117-129. doi: 10.1055/s-2005-867080

Epstein, A. W. (1984). The contribution of cerebral hemispheric disease to the understanding of dream type and content. Research Communications in Psychology, Psychiatry \& Behavior, 9(1), $15-30$.

Fisher, C. (1973). Biología de los sueños y psicoanálisis. España: Siglo Veintiuno de España.

Foulkes, D. (1982). Gramática de los Sueños. Buenos Aires: Paidós.

Freud, S. (1966). La Interpretación de los Sueños. Madrid: Alianza Editorial.

Frith, C. D. (2007). The social brain? Philosophical Transactions of the Royal Society B, 362, 671678. doi: $10.1098 /$ rstb.2006.2003

Gershon, E. S., \& Rieder, R. O. (1992). Major disorders of mind and brain. Scientific American, 267(5), 126-133. doi: 10.1038/scientificamerican0992-126

Gibbs, W. W. (1995). Seeking the criminal element. Scientific American, 272(3), 102-110. doi: 10.1038/scientificamerican0395-100

Goldberg, E. (2002). El Cerebro Ejecutivo: Los Lóbulos Frontales y la Mente Civilizada. Barcelona: Editorial Crítica.

Grønli, J., \& Ursin, R. (2009). [Basic sleep mechanisms]. Tidsskrift for den Norske laegeforening: tidsskrift for praktisk medicin, ny raekke, 129(17), 1758-1761. doi: 10.4045/tidsskr.08.0465

Hobson, J. A., \& Stickgold, R. (1995). The conscious state paradigm: a neurocognitive approach to waking, sleeping, and dreaming. In M. S. Gazzaniga (Ed.), The Cognitive Neurosciences. MIT Press.

Hong, C. C., Gillin, J. C., Dow, B. M., Wu, J., \& Buchsbaum, M. S. (1995). Localized and lateralized cerebral glucose metabolism associated with eye movements during REM sleep and wakefulness: a positron emission tomography (PET) study. Sleep, 18(7), 570-580.

Jouvet, M., Sastre, J. P., \& Sakai, K. (1981). Toward an etho-ethnology of dreaming. In I. Karacan (Ed.). Psychophysiological Aspects of Sleep (pp. 1204-1214). New Jersey: Medical Publications.

Kerr, N. H., \& Foulkes, D. (1981). Right hemispheric mediation of dream visualization: A case study. Cortex, 17(4), 603-609. doi: 10.1016/S0010-9452(81)80066-4

Koukkou, M., \& Lehmann, D. (1983). Dreaming: the functional state-shift hypothesis. The British Journal of Psychiatry, 143(3), 221-231. doi: 10.1192/bjp.142.3.221

LaBerge, S. (1990). Lucid dreaming: Psychophysiological studies of consciousness during REM sleep. In R. R. Bootzin, J. F. Kihlstrom, \& D. L. Sctactor (Eds), Sleep and Cognition (pp. 109126). Washington, D. C.: American Psychological Association. doi: 10.1037/10499-008 
Luria, A. R. (1974). El Cerebro en Acción. Barcelona: Fontanella.

Madsen, P. L. (1993). Blood flow and oxygen uptake in the human brain during various states of sleep and wakefulness. Acta Neurologica Scandinavica, 88(148), 5-25.

Magoun, H. W. (1964). El Cerebro Despierto. México: La Prensa Médica Mexicana.

Maquet, P., Péters, J. M., Aerts, J., Delfiore, G., Degueldre, C., Luxen, A., \& Franck, G. (1996). Functional neuroanatomy of human rapid-eye-movement sleep and dreaming. Nature, 383(6596), 163-166. doi: 10.1038/383163a0

Murri, L., Bonanni, E., Stefanini, A., Goldstein, L., Navona, C., \& Denoth, F. (1992). Neurological approaches to the dream problem. In J. S. Antrobus, \& M. Bertini. The Neuropsychology Of Sleep and Dreaming (pp. 87-98). New Jersey: Psychology Press.

Muzur, A., Pace-Schott, E. F., \& Hobson, J. A. (2002). The prefrontal cortex in sleep. Trends in Cognitive Sciences, 6(11), 475-481. doi: 10.1016/S1364-6613(02)01992-7

Nofzinger, E. A. (2005). Neuroimaging and sleep medicine. Sleep Medicine Reviews, 9(3), 157172. doi: 10.1016/j.smrv.2004.07.003

Noreika, V., Windt, J. M., Lenggenhager, B., \& Karim, A. A. (2010). New perspectives for the study of lucid dreaming: From brain stimulation to philosophical theories of self-consciousness. International Journal of Dream Research, 3(1), 36-45.

Peña-Casanova, J., Roig-Rovira, T., Bermudez, A., \& Tolosa-Sarro, E. (1985). Optic aphasia, optic apraxia, and loss of dreaming. Brain and Language, 26(1), 63-71. doi: 10.1016/0093-934$\mathrm{X}(85) 90028-8$

Peterson, N. D., Henke, P. G., \& Hayes, Z. (2002). Limbic system function and dream content in university students. The Journal of Neuropsychiatry and Clinical Neurosciences, 14(3), 283288. doi: 10.1176/jnp.14.3.283

Rechtschaffen, A., \& Kales, A. (1968). A Manual of Standardized Terminology, Techniques and Scoring System for Sleep Stages of Human Subjects. Washington DC: Public Health Service, USA Government Printing Office.

Sakai, F., Meyer, J. S., Karacan, I., Derman, S., \& Yamamoto, M. (1980). Normal human sleep: Regional cerebral hemodynamics. Annals of Neurology, 7(5), 471-478. doi: 10.1002/ ana.410070514

Schenck, C. H., Bundlie, S. R., Patterson, A. L., \& Mahowald, M. W. (1987). Rapid eye movement sleep behavior disorder. JAMA, 257(13), 1786-1789. doi: 10.1001/jama.1987. 03390130104038

Schenck, C. H., Milner, D. M., Hurwitz, T. D., Bundlie, S. R., \& Mahowald, M. (1989). Sleeprelated injury in 100 adult patients: A polysomnographic and clinical report. American Journal of Psychiatry, 146(9), 1166-1172. doi: 10.1176/ajp.146.9.1166

Schwartz, S., \& Maquet, P. (2002). Sleep imaging and the neuro-psychological assessment of dreams. Trends in Cognitive Sciences, 6(1), 23-30. doi: 10.1016/S1364-6613(00)01818-0

Solms, M. (2000). Freudian dream theory today. The Psychologist, 13(12), 618-619.

Stretton, J., \& Thompson, P. J. (2012). Frontal lobe function in temporal lobe epilepsy. Epilepsy Research, 98(1), 1-13. doi: 10.1016/j.eplepsyres.2011.10.009

Téllez, A. (1998). Trastornos del Sueño: Diagnóstico y Tratamiento. México: Trillas.

Téllez, A., Téllez, H., Tirado, H., Butcher, E., Railey, C., \& Mendoza, M. E. (2002). Atención, Aprendizaje y Memoria: Aspectos psicobiológicos. México: Trillas.

Tsvetkova, L. S. (1996). Acalculia: Aproximación neuropsicológica al análisis de la alteración y la rehabilitación del cálculo. En F. Ostrosky, A. Ardila, \& R. Chayo (Eds.), Rehabilitación Neuropsicológica (pp. 114-131). México: Planeta.

Vandekerckhove, M., \& Cluydts, R. (2010). The emotional brain and sleep: An intimate relationship. Sleep Medicine Reviews, 14(4), 219-226. doi: 10.1016/j.smrv.2010.01.002 
Vogel, G. W. (1979). A motivational function of REM sleep. In: R. Drucker-Colín, M. Shkurovich, \& M. B. Sterman (Eds.), Functions of Sleep (pp. 233-250). New York: Academic Press. doi: 10.1016/B978-0-12-222340-2.50015-X

Vogel, G. W., Vogel, F., McAbee, R. S., \& Thurmond, A. J. (1980). Improvement of depression by REM sleep deprivation. Archives of General Psychiatry, 37(3), 247-253. doi: 10.1001/ archpsyc.1980.01780160017001

Wagner, A. D., Schacter, D. L., Rotte, M., Koutstaal, W., Maril, A., Dale, A. M., Rosen, B. R., \& Buckner, R. L. (1998). Building memories: Remembering and forgetting of verbal experiences as predicted by brain activity. Science, 281(5380), 1188-1191. doi: 10.1126/ science.281.5380.1188

Welsh, M. C., \& Pennington, B. F. (1988) Assessing frontal lobe functioning in children: Views from developmental psychology. Developmental Neuropsychology, 4(3), 199-230. doi: $10.1080 / 87565648809540405$

Žemaityte, D., Varoneckas, G., \& Sokolov, E. (1984). Heart rhythm control during sleep. Psychophysiology, 21(3), 279-289. doi: 10.1111/j.1469-8986.1984.tb02935.x

Original manuscript received February 15, 2016

Revised manuscript accepted May 29, 2016

First published online December 01, 2016 